\title{
Visual perception changes and optical stability after intracorneal ring segment implantation: comparison between 3 months and I year after surgery
}

\author{
This article was published in the following Dove Press journal: \\ Clinical Ophthalmology \\ 28 July 2011 \\ Number of times this article has been viewed
}

Juliane de Freitas Santos

Paranhos

Marcos Pereira Ávila

Augusto Paranhos Jr

Paulo Schor

Federal University of São Paulo, São Paulo, Brazil
Correspondence: Juliane de FS Paranhos Hospital da Visão, Rua 38,

no. 300, Setor Marista, 74150250,

Goiania, GO, Brazil

$\mathrm{Tel}+5562 \quad 811$ 15-3905

Fax +55 62 40I2-2525

Email ju.fsp@hotmail.com
Purpose: To prospectively evaluate intracorneal ring segment (ICRS) implantation on quality of life (QoL) of patients with keratoconus changes and identify factors responsible.

Methods: Sixty-nine eyes of 42 keratoconus patients were implanted with the Keraring (Mediphacos, Belo Horizonte, Brazil). Best corrected visual acuity (BCVA), refraction, and steep keratometry were analyzed 3 months and 1 year after surgery. All patients self-administered the National Eye Institute Refractive Error Quality of life instrument at 2 time points: after having worn best correction for at least 30 days since evaluation (mean 4 months after surgery) and 1 year after surgery. To analyze if the use of the appropriate correction at 1 year follow up had any impact on visual acuity and V-QoL, patients were divided into 2 groups: group A (appropriate correction) and B (not appropriate correction).

Results: After 1 year, QoL changes related to scales 'clarity of vision', 'near vision', and 'far vision'. Keratometric values, sphere, and spherical equivalent did not differ significantly between 3 months and 1 year postoperative. Cylinder increase was statistically but not clinically significant. Binocular BCVA did not change 1 year after surgery in group A and showed a clinically significant impairment in group B. A year after surgery, 18 patients did not use correction suggested by a physician 3 months after surgery. QoL was not statistically different 1 year after surgery between group A and group B.

Conclusion: Our findings show that the way keratoconic patients see is difficult to analyze using only quantitative and 1-visit metrics. They highlight the importance of patients' self perception and performing longitudinal analysis to consider neural compensation to optical changes from surgery.

Keywords: keratoconus, cornea, quality of life

\section{Introduction}

Keratoconus is a chronic disease affecting young people. Early symptoms are usually noticeable in the early 20 s. $^{1}$ The disease is progressive and vision may be seriously impaired, causing an important negative impact on patients' quality of life (QoL). ${ }^{2}$ In the early stages, vision can be improved by the use of spectacles but with disease progression contact lenses or surgery are necessary to restore vision.

Penetrating keratoplasty is the most common surgery to treat keratoconus. This yields good results but with potential complications including graft failure, rejection, glaucoma, irregular astigmatism, cataract, and glare. ${ }^{1,3,4}$ Rehabilitation for 1 year usually follows surgery. ${ }^{3}$ Intracorneal ring segment (ICRS) implantation is a surgical option 
to avoid corneal graft. It has an arc-shortening effect and so the central portion of the cornea tends to flatten and the peripheral area adjacent to ring insertion is displaced forward. Because the procedure does not involve tissue removal it has fewer intraoperative and postoperative risks and faster vision rehabilitation, of about 3 months after surgery. ${ }^{5-9}$

A study conducted by the CLEK group ${ }^{2}$ concluded that QoL is seriously affected in keratoconus patients and continues to decline over time, but an earlier study by our group showed that ICRS implantation improves visual QoL (V-QoL). ${ }^{10}$

The National Eye Institute Refractive Error Quality of Life (NEI-RQL) is a vision-targeted survey to assess the impact of refractive error and its correction on day-to-day life. ${ }^{11}$ The purpose of this study is to prospectively evaluate if V-QoL changes 1 year after ICRS implantation and to identify the factors responsible for any changes that occur.

\section{Materials and methods Patient selection}

Ophthalmologists of Goiânia, Goiás, Brazil working in the Department of Ophthalmology of the Federal University of Goiás were asked to refer patients with keratoconus indicated for ICRS implantation. Indications for ICRS implantation were poor visual acuity with spectacles, intolerance to contact lenses, steep keratometric reading $<70$ diopters (D), and clear central cornea. Patients who had never tried contact lenses were tested and, if lenses fitted well, the patients were returned to their physician.

\section{Inclusion criteria}

Patients included in this study were aged 19 to 39 years. They had keratoconus in both eyes, symmetrical or asymmetrical, diagnosed by corneal topography with clear central corneas, poor visual acuity with spectacles, and intolerance to contact lenses. ${ }^{1}$ The steepest keratometric value was $<70$ D.

\section{Exclusion criteria}

Patients were excluded from the study if they had other ocular diseases besides keratoconus, if they had systemic conditions with a potential to cause refractive instability (pregnancy, diabetes), or if they were illiterate.

\section{Surgical technique and postoperative care} All surgeries were performed by the same surgeon (JFSP) in 2007 between June and October. The manufacturer's nomogram was used to calculate the implantation of the ICRS.
For all surgeries the $160^{\circ}$ Keraring (Mediphacos, Belo Horizonte, Brazil) was implanted with thickness varying from 150 to $350 \mu \mathrm{m}$. Vigamox solution (moxifloxacin $\mathrm{HCl}$ ophthalmic solution $0.5 \%$, Alcon Inc, Fort Worth, TX) was instilled 4 times, 1 hour before surgery, and pilocarpine (pilocarpine hydrochloride $10 \mathrm{mg} / \mathrm{mL}$, Allergan Inc, Irvine, CA) once before surgery. The surgery was performed under topical anesthesia (proxymetacaine chlorhydrate $0.5 \%$, Anestalcon, Alcon). Polyvinylpyrrolidone-iodine (PVPI, Ophthalmos, Inc, São Paulo, Brazil) was used over the conjunctiva and cornea 5 minutes before surgery. A circular marker centered on the reflex of microscope light on the cornea was used to create 2 concentric circles of 5 and $7 \mathrm{~mm}$. A radial incision set at $80 \%$ of the corneal pachymetry at the steepest corneal axis was made, then 1 or 2 concentric stromal tunnels with an internal radius of $2.5 \mathrm{~mm}$ and an attempted extension of $170^{\circ}$ were constructed with an appropriate curved spatula, and the ring segments implanted in these tunnels. After surgery patients were instructed to use topical antibiotics and corticosteroids (Vigamox eyedrops 3 times a day for 7 days and prednisolone acetate 1\%, Falcon, 4 times a day for 10 days).

\section{Evaluation and analysis}

Refraction, slit lamp biomicroscopy, indirect ophthalmoscopy, and corneal topography (Medmont) were evaluated at 2 time points: 3 months and 1 year after surgery.

Best corrected visual acuity (BCVA) with current correction (spectacles, contact lenses, or no correction) of operated eyes and binocular BCVA were assessed when patients had been wearing their best correction for at least 30 days after initial post-surgical evaluation (mean 4 months after surgery) and 1 year after surgery. The LogMAR chart was used to measure visual acuity.

Keratoconus patients self-administered a Portuguese validated version of the NEI-RQL instrument. ${ }^{12}$ Patients answered the survey after ICRS implantation (Keraring), when they had been using best correction for at least 30 days after evaluation (mean 4 months after surgery) and 1 year after surgery. The survey consisted of 42 items used to build 13 scales (clarity of vision, expectations, near vision, far vision, diurnal fluctuations, activity limitations, glare, symptoms, dependence on correction, worry, suboptimal correction, appearance, and satisfaction with correction), which were transformed linearly to a 0 to 100 possible range. Lower scores corresponded with lower or worse QoL on each subscale. The NEI-RQL was scored according to the guidelines set out by its authors. ${ }^{13}$ 
The patient data were first analyzed all together. Then patients were divided into 2 groups: group A included patients who were wearing the appropriate correction as suggested by their physician and group B included patients who were not using the suggested correction at 1 year.

\section{Ethical approval}

This study was approved by the ethics committees of the Federal University of Goiás and Federal University of São Paulo. All patients read and signed consent forms.

\section{Statistical analysis}

Paired $t$ and Mann-Whitney nonparametric tests were used to compare binocular BCVA and NEI-RQL scales twice after surgery. For measurements taken per eye (sphere, cylinder, spherical equivalent, steep keratometric reading $\left[\mathrm{K}_{\max }\right]$ and visual acuity), generalized estimation equation models were applied in order to take the within-subject correction into account. Analysis of variance was used to compare groups $\mathrm{A}$ and $\mathrm{B}$ in order to evaluate whether use of adequate correction influenced QoL.

The level of significance adopted was 0.05. Statistics were calculated using SPSS for Windows software, version 17.0 and SAS, version 9.0.

\section{Results}

Forty-two patients were included in this study and answered the questionnaire 4 months after surgery, of which 33 (78.6\%) returned and answered the questionnaire 1 year after surgery. Of the 9 patients that did not have QoL data 1 year after surgery, 6 did not return to be examined, 1 did not answer the questionnaire, and 2 had ring extrusion. Of the 42 patients, $19(45.2 \%)$ were male and $23(54.8 \%)$ were female. The average age was $24.9 \pm 5$ years (range 18 to 39 years). Most patients $(66.7 \%)$ were undertaking or had completed high school, $26.2 \%$ were at university, and $7.1 \%$ had received basic education.

Twenty-seven, of the total of 42 patients, had surgery in both eyes and the rest underwent surgery in only 1 eye, representing a total of 69 eyes with ICRS implantation. Twelve patients had surgery performed only in 1 eye due to good vision in the other eye. Three patients did not meet the criteria for ICRS implantation in their other eye and these eyes had a significant visual acuity impairment.

Data were analyzed from the 33 patients with complete data, who had returned 1 year after surgery.

There was no statistically significant change in steep keratometric $\left(\mathrm{K}_{\max }\right)$ reading 3 months (mean $\left.52.64 \pm 0.67\right)$ and 1 year (mean $52.84 \pm 0.63)$ after surgery $(P=0.4715)$. Sphere and spherical equivalent data did not show any statistically significant change between these 2 time points after surgery ( $P=0.269$ and $P=0.075$ respectively). Cylinder had a statistically but not clinically significant increase 1 year after ICRS implantation $(P=0.014)$ (Table 1).

The treated eyes decreased by 1 line of BCVA 1 year after surgery $(0.25[0.02]$ to $0.34[0.03] P=0.0091)$, which is statistically significant. Mean binocular BCVA also had a statistically significant worsening $(0.07[0.14]$ to 0.14 [0.17] $P=0.021)$.

Of the 42 patients, $36(85.7 \%)$ had data related to correction in current use 1 year after surgery. Eighteen (50\%) patients wore a correction different from that suggested by a physician 3 months after surgery (Table 2). Twenty-four (66.7\%) patients did not need to change their initial correction 1 year after surgery. Of the 14 patients who were not using any correction 1 year after surgery, 12 actually needed to use some form of correction ( 9 spectacles, 2 soft contact lenses, and 1 patient, rigid gas permeable lenses).

There was a statistically significant reduction in the scores of the scales related to clarity of vision, near vision, and far vision (Table 3). The QoL of these scales had a significant worsening 1 year after surgery $(P=0.703, P=0.892$, $P=0.263$, respectively). The scores of the other scales and the general scale did not have a statistically significant difference between the 2 times of evaluation $(P>0.05)$.

There was no statistical difference between QoL scales in groups A and B 1 year after surgery. The results of these 2 groups for QoL in the scales of clarity of vision $(P=0.703)$, near vision $(P=0.892)$, and far vision $(P=0.263), 1$ year after surgery, were similar. Visual acuity was different in these 2 groups $(P=0.047)$. Group A had no difference in binocular BCVA between 4 months and 1 year after surgery $(0.10[0.15]$ to $0.12[0.14] P=0.189)$ and group $\mathrm{B}$ had an almost statistically significant worsening $(0.01[0.09]$ to 0.19 [0.24] $P=0.053$ ). Group B lost 2 lines in mean binocular BCVA, which was clinically significant (Figure 1).

Table I Comparison of sphere, cylinder, spherical equivalent and $\mathrm{K}_{\max } 3$ months and I year after Keraring ICRS implantation

\begin{tabular}{llll}
\hline & $\begin{array}{l}\text { 3 months after surgery } \\
\text { Mean (SD) }\end{array}$ & $\begin{array}{l}\text { I year after surgery } \\
\text { Mean (SD) }\end{array}$ & $P$-value \\
\hline Spherical & $\mathrm{I} .8 \mathrm{I}(0.30)$ & $1.95(0.26)$ & 0.2696 \\
Cylinder & $\mathrm{I} .78(0.18)$ & $1.96(0.16)$ & 0.0144 \\
$\mathrm{SE}$ & $\mathrm{I} .68(0.2 \mathrm{I})$ & $1.82(0.18)$ & 0.0752 \\
$\mathrm{~K}_{\max }(\mathrm{D})$ & $52.64(0.67)$ & $52.84(0.63)$ & 0.4715 \\
\hline
\end{tabular}

Notes: ${ }^{a}$ Correction within subjects was taken into account; $\mathrm{K}_{\max }=$ steep keratometric value. 
Table 2 Comparison between patients' current correction 4 months and I year after ICRS implantation

\begin{tabular}{|c|c|c|c|c|c|c|c|}
\hline & & & \multicolumn{4}{|c|}{ Correction in use I year after surgery } & \multirow[t]{2}{*}{ Total } \\
\hline & & & Nothing & Spectacles & Soft lenses & RGP & \\
\hline Correction in use & Nothing & $\mathrm{N}$ & 6 & - & - & - & 6 \\
\hline 4 months after & & $\%$ & $100.0 \%$ & & & & $100.0 \%$ \\
\hline \multirow[t]{8}{*}{ surgery } & Spectacles & $\mathrm{N}$ & 2 & 16 & - & - & 18 \\
\hline & & $\%$ & $11.1 \%$ & $88.9 \%$ & & & $100.0 \%$ \\
\hline & Soft contact lenses & $\mathrm{N}$ & 2 & I & I & - & 4 \\
\hline & & $\%$ & $50.0 \%$ & $25.0 \%$ & $25.0 \%$ & $0.0 \%$ & $100.0 \%$ \\
\hline & RGP & $\mathrm{N}$ & 4 & 2 & I & I & 8 \\
\hline & & $\%$ & $50.0 \%$ & $25.0 \%$ & $12.5 \%$ & $12.5 \%$ & $100.0 \%$ \\
\hline & Total & $\mathrm{N}$ & 14 & 19 & 2 & I & 36 \\
\hline & & $\%$ & $38.9 \%$ & $52.8 \%$ & $5.6 \%$ & $2.8 \%$ & $100.0 \%$ \\
\hline
\end{tabular}

Abbreviations: ICRS, intra-corneal ring segment; RGP, rigid gas permeable.

\section{Discussion}

Neural compensation occurs in keratoconus patients due to long-term optical blur. A study showed that due to neural compensation keratoconus patients had statistically better high and low contrast visual acuity than those with normal vision exposed to keratoconic aberrations with the use of

Table 3 Comparison between NEI-RQL scores 4 months and I year after Keraring ICRS implantation

\begin{tabular}{|c|c|c|c|}
\hline Scales & 4 months & I year after & $P$-value \\
\hline \multicolumn{4}{|c|}{ Clarity of vision } \\
\hline Mean (SD) & $77.6(21.5)$ & $67.7(21.5)$ & 0.008 \\
\hline \multicolumn{4}{|l|}{ Expectation } \\
\hline Mean (SD) & l $4.7(23.1)$ & 19.1 (33.2) & 0.422 \\
\hline \multicolumn{4}{|l|}{ Near vision } \\
\hline Mean (SD) & $81.3(19.4)$ & $72.3(18.1)$ & 0.003 \\
\hline \multicolumn{4}{|l|}{ Far vision } \\
\hline Mean (SD) & $80.5(17.0)$ & $72.5(19.5)$ & 0.017 \\
\hline \multicolumn{4}{|c|}{ Vision fluctuation } \\
\hline Mean (SD) & $64.4(23.9)$ & $60.0(26.1)$ & 0.364 \\
\hline \multicolumn{4}{|c|}{ Activity limitation } \\
\hline Mean (SD) & $86.0(24.3)$ & $83.3(21.7)$ & 0.528 \\
\hline \multicolumn{4}{|l|}{ Glare } \\
\hline Mean (SD) & $57.4(27.2)$ & $52.6(29.2)$ & 0.326 \\
\hline \multicolumn{4}{|c|}{ Ocular symptoms } \\
\hline Mean (SD) & $60.6(18.8)$ & $57.1(19.0)$ & 0.165 \\
\hline \multicolumn{4}{|c|}{ Dependence on correction } \\
\hline Mean (SD) & $50.6(34.9)$ & $53.3(29.1)$ & 0.491 \\
\hline \multicolumn{4}{|c|}{ Suboptimal correction } \\
\hline Mean (SD) & $22.8(29.8)$ & $15.4(25.6)$ & 0.134 \\
\hline \multicolumn{4}{|l|}{ Worry } \\
\hline Mean (SD) & $88.2(19.2)$ & $88.2(24.2)$ & $>0.999$ \\
\hline \multicolumn{4}{|l|}{ Appearance } \\
\hline Mean (SD) & $87.1(23.0)$ & $85.7(23.0)$ & 0.734 \\
\hline \multicolumn{4}{|c|}{ Satisfaction with correction } \\
\hline Mean (SD) & $81.8(19.3)$ & $82.9(16.4)$ & $0.7 I I$ \\
\hline \multicolumn{4}{|l|}{ General scale } \\
\hline Mean (SD) & $65.6(13.3)$ & $62.2(12.8)$ & 0.110 \\
\hline
\end{tabular}

Abbreviations: ICRS, intra-corneal ring segment; NEI-RQL, National Eye Institute Refractive Error Quality of Life. adaptive optics. The magnitude of their response to the correction of higher-order aberrations was different from that expected and they did not achieve the visual benefit predicted. ${ }^{14,15}$ Therefore the assessment of V-QoL through questionnaires like NEI-RQL can be used as a suitable tool to analyze the impact of optical changes in keratoconic eyes due to surgical procedures.

This was a longitudinal prospective study that evaluated ICRS implantation results at 2 time points: 4 months and 1 year after surgery. Sphere and spherical equivalent did not change 1 year after surgery $(P>0.05)$. Cylinder increase in this period was statistically but not clinically significant (1.78D [0.18] to $1.98 \mathrm{D}[0.16] ; P=0.014)$. There was no statistical significant change in mean steep keratometric readings $\left(\mathrm{K}_{\max }\right)(52.64$ [0.67] to 52.84 [0.63]; $P=0.4715)$. The operated eyes lost a mean of 1 line of BCVA 1 year after surgery. One year after surgery, $50 \%$ of the patients were not using the correction (group B) suggested by their physician 3 months after surgery. So, except for the difference in

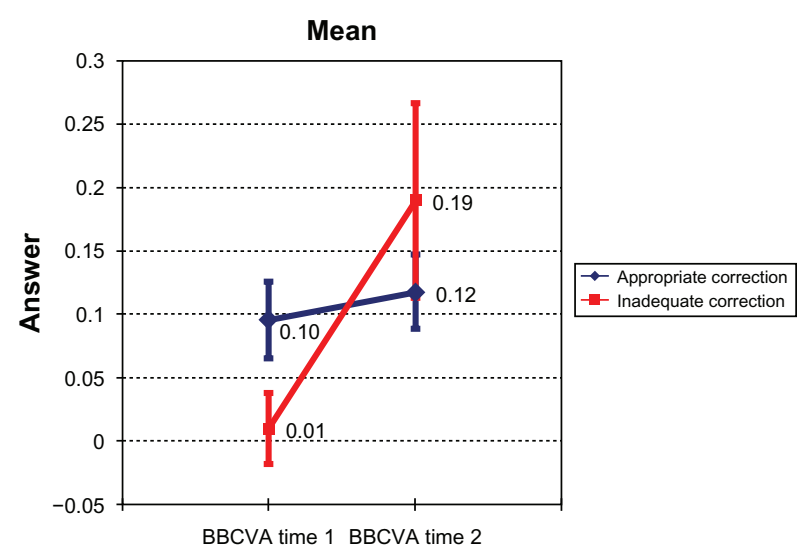

Figure I Quality of life answers for mean binocular best corrected visual acuity (BBCVA) for groups $A$ and $B$. 
visual acuity between groups A and B there was no other important optical change in these patients 1 year after ICRS implantation.

Quality of life changed 1 year after Keraring implantation in relation to NEI-RQL scales 'clarity of vision', 'near vision', and 'far vision'. There was no difference in V-QoL between group A (using the correction suggested by physician and no visual acuity changes) and B (using a different correction and 2 lines lost) even in scales of clarity of vision $(P=0.703)$, near vision $(P=0.892)$, and far vision $(P=0.263)$, showing that visual acuity did not influence subjective results. These results consolidate previous findings that visual acuity is not a good parameter to evaluate visual function. ${ }^{16-19} \mathrm{~K}_{\max }(P=0.4715)$ and sphere $(P=0.2696)$ remained stable and cylinder did not show a clinically significant change, demonstrating that these parameters do not assist in explaining changes to these scales.

One explanation for these results is that after surgery, patients noticed a great improvement in their sharpness of vision and detailed reading activities related to near and far vision, but as time went by they noticed that although they had acceptable visual acuity (0.12 logMAR in group A and 0.19 $\log$ MAR in group B), their vision was not as good as in people with normal vision and they still had some impairment, which was reflected in their answers 1 year after surgery. Another possibility is that 1 year after surgery patients were not totally adapted to the optical changes induced by the surgery. This is also in agreement with findings that measurement of visual function in keratoconus patients is complex due to long-term adaptation for optical blur. Patients may not achieve the results predicted by quantitative metrics and it is the changes in clinical measurements over time that influence patients' perception. ${ }^{2,14,15}$ This highlights the importance of longitudinal studies such as this one in order to analyze surgical results in keratoconus patients.

The impact of corneal transplantation in keratoconus patients' QoL is not totally understood. Some studies have shown improvement and others not. ${ }^{3,20}$

Our results are in accordance with others showing the importance of a subjective approach and to perform longitudinal analysis. ${ }^{3,4,20}$ The way keratoconic patients see and how well they compensate changes in their vision due to surgery interference is difficult to analyze using only quantitative and 1-visit metrics. It is important to consider neural compensation changes in the retinal image caused by the surgery and evaluate the impact of optical changes in keratoconus patients' visual function. This study evaluated subjective outcomes of Keraring ICRS implantation over 1 year and the results showed that general V-QoL is sustained over this period. Of the 13 scales, only 3 , clarity of vision, near vision, and far vision, showed significant worsening 1 year after surgery, although they still presented high scores (>70 points), showing that V-QoL remained good.

\section{Disclosure}

None of the authors have any financial interests in other products or techniques described herein.

\section{References}

1. Rabinowitz YS. Keratoconus. Surv Ophthalmol. 1998;42(4):297-319.

2. Kymes SM, Walline JJ, Zadnik K, Sterling J, Gordon MO. Changes in the quality-of-life of people with keratoconus. Am J Ophthalmol. 2008;145(4):611-617.

3. Brahma A, Ennis F, Harper R, Ridgway A, Tullo A. Visual function after penetrating keratoplasty for keratoconus: a prospective longitudinal evaluation. Br J Ophthalmol. 2000;84(1):60-66.

4. Cavalcanti MTD, Mahon M, da Nóbrega DAT, de Aguiar Remíglio MC, Pires CS. Ceratocone: resultados visuais, complicações e qualidade de vida após ceratoplastia penetrante realizada por médico residente. Arquivos Brasileiros de Oftalmologia. 2004;67:4.

5. Colin J, Velou S. Current surgical options for keratoconus. J Cataract Refract Surg. 2003;29(2):379-386.

6. Alio JL, Shabayek MH, Artola A. Intracorneal ring segments for keratoconus correction: long-term follow-up. J Cataract Refract Surg. 2006;32(6):978-985.

7. Miranda D, Sartori M, Francesconi C, Allemann N, Ferrara P, Ferrara CM. Intrastromal corneal ring segments for severe keratoconus. $J$ Refract Surg. 2003;19(6):645-653.

8. Pinero DP, Alio JL, El Kady B, et al. Refractive and aberrometric outcomes of intracorneal ring segments for keratoconus: mechanical versus femtosecond-assisted procedures. Ophthalmology. 2009;116(9): $1675-1687$.

9. Pinero DP, Alio JL. Intracorneal ring segments in ectatic corneal diseasea review. Clin Exp Ophthalmol. 2010;38:154-167.

10. de Freitas Santos Paranhos J, Avila MP, Paranhos A Jr, Schor P. Evaluation of the impact of intracorneal ring segments implantation on the quality of life of patients with keratoconus using the NEI-RQL (National Eye Institute Refractive Error Quality of life) instrument Br J Ophthalmol. 2010;94(1):101-105.

11. Hays RD, Mangione CM, Ellwein L, Lindblad AS, Spritzer KL, McDonnell PJ. Psychometric properties of the National Eye Institute-Refractive Error Quality of Life instrument. Ophthalmology. 2003;110(12):2292-2301.

12. Nunes MN, Vitor C, Schor P. Validação de versão em língua portuguesa do questionário NEI-RQL como instrumento da qualidade de vida relacionada à visão, em candidatos a cirurgia refrativa. Rev Bras Oftalmol. 2004;63(2):110-118.

13. Hays RD SK. National Eye Institute Refractive Error Quality of Life Instrument (NEI-RQL-42). Version 1.0: a manual for scoring and use. Los Angeles, CA: Rand Health Sciences; 2002.

14. Sabesan R, Yoon G. Neural compensation for long-term asymmetric optical blur to improve visual performance in keratoconic eyes. Invest Ophthalmol Vis Sci. 2010;51(7):3835-3839.

15. Sabesan R, Yoon G. Visual performance after correcting higher order aberrations in keratoconic eyes. J Vis. 2009;9(5):6.1-10.

16. Mannis MJ, Zadnik K, Johnson CA. The effect of penetrating keratoplasty on contrast sensitivity in keratoconus. Arch Ophthalmol. 1984;102(10):1513-1516. 
17. Carney LG, Lembach RG. Management of keratoconus: comparative visual assessments. CLAO J. 1991;17(1):52-58.

18. Uiters E, van den Borne B, van der Horst FG, Volker-Dieben HJ. Patient satisfaction after corneal transplantation. Cornea. 2001;20(7): 687-694.
19. Applegate RA, Sarver EJ, Khemsara V. Are all aberrations equal? $J$ Refract Surg. 2002;18(5):S556-S562.

20. Yildiz EH, Cohen EJ, Virdi AS, Hammersmith KM, Laibson PR, Rapuano CJ. Quality of life in keratoconus patients after penetrating keratoplasty. Am J Ophthalmol. 2010;149(3):416-422. e1-e2.

\section{Publish your work in this journal}

Clinical Ophthalmology is an international, peer-reviewed journal covering all subspecialties within ophthalmology. Key topics include: Optometry; Visual science; Pharmacology and drug therapy in eye diseases; Basic Sciences; Primary and Secondary eye care; Patient Safety and Quality of Care Improvements. This journal is indexed on

\section{Dovepress}

PubMed Central and CAS, and is the official journal of The Society of Clinical Ophthalmology (SCO). The manuscript management system is completely online and includes a very quick and fair peer-review system, which is all easy to use. Visit http://www.dovepress.com/ testimonials.php to read real quotes from published authors. 